\title{
UM ESTUDO DE CASO ENVOLVENDO BUSINESS INTELLIGENCE COMO INSTRUMENTO DE APOIO À CONTROLADORIA
}

\author{
A CASE STUDY OF BUSINESS INTELLIGENCE AS \\ AN INSTRUMENT TO SUPPORT CONTROLLERSHIP
}

\author{
LUCIANE REGINATO \\ Mestre em Ciências Contábeis \\ pela Universidade do Vale do Rio dos Sinos - RS \\ E-mail: Iuciregi@terra.com.br
}

\author{
AUSTER MOREIRA NASCIMENTO \\ Professor Titular do Programa de Pós-Graduação em Ciências Contábeis \\ da Universidade do Vale do Rio dos Sinos - RS \\ E-mail: auster@unisinos.br
}

\section{RESUMO}

Esta pesquisa buscou investigar a contribuição das ferramentas da tecnologia da informação, especificamente as de Business Intelligence (BI), para a área de controladoria exercer sua função de suprir o processo decisório com as informações úteis por ele requeridas. O estudo foi conduzido através de pesquisa de campo, especialmente de um estudo de caso, em que o assunto pôde ser analisado em detalhes. Para tanto, foram aplicadas entrevistas, orientadas por um roteiro construído para esse fim e por um protocolo previamente elaborado para o estudo, bem como foram analisados documentos internos, registros em arquivos e observação direta como fonte de evidências. O período de abrangência da análise dos dados foi de agosto de 2003 a dezembro de 2005, tendo sido possível observar a situação da empresa objeto do estudo antes e depois da implementação das ferramentas de BI. Após a análise das entrevistas, dos indicadores das áreas e de seu impacto no resultado global da empresa, concluiuse que as referidas ferramentas podem auxiliar a controladoria na função de prover informações confiáveis, úteis e tempestivas ao processo decisório, por meio de sua flexibilização e dinamicidade, proporcionando, como conseqüência, a melhoria dos resultados das áreas organizacionais, bem como da empresa como um todo.

Palavras-chave: Informação; Controladoria; Dimensões de Controle; Tecnologia da Informação; Business Intelligence.

\section{ABSTRACT}

This research examined the contribution of tools provided by Information Technology and specifically Business Intelligence (BI), for the controllership area to perform its function of supporting the decision-making process with useful information. The study was carried out through a field research, specifically a case study, in which the subject could be analyzed in detail. Therefore, interviews were held, guided by a structured script and by a previously elaborated form. Internal documents, files and direct observations were also analyzed as sources of evidence. The period covered by data analysis was from August 2003 until December 2005, during which we could observe the company's situation before and after the implementation of the BI tools. After the analysis of the interviews, the area indicators and the impact of the tools' implementation on the company's economic results, it was concluded that the BI tools can help the controllership area in its function to provide reliable, useful and timely information to the decision-making process, through its flexibility and dynamics, thus contributing to the improvement of the organizational areas' and the company's results.

Keywords: Information, Controlling, Dimensions of Control, Information Technology, Business Intelligence. 


\section{INTRODUC̣ÃO}

A interação entre as áreas de uma empresa requer a existência de uma forma organizada para o consumo de um dos principais recursos que esse processo de integração demanda: a informação, a qual, contudo, pode não satisfazer às expectativas de seus usuários se não estiver acompanhada de atributos que a tornem, realmente, útil ao processo decisório, isto é, se não for acurada, tempestiva e adequadamente comunicada àqueles que dela necessitam para o exercício de suas atividades.

Nesse aspecto, a informação e sua comunicação adquirem contornos estratégicos, dado o seu poder de interferir na qualidade das decisões tomadas. Elas podem ser um dos fatores que explicam o grau de congruência entre as ações implementadas pelos gestores e as expectativas da administração da empresa, tornando-se a moldura de todo o processo de gestão. Esse raciocínio é perceptível na ênfase dada por Moscove, Simkin e Bagranoff (2002, p.22), os quais entendem que "o sucesso ou fracasso da empresa está ligado à forma como a informação é gerenciada e utilizada".

A informação como um recurso relevante ao processo decisório e, em conseqüência, para a continuidade da empresa, adquire atenção especial no que se refere à sua acurácia e tempestividade, sendo esse o mote para o surgimento de áreas na empresa especificamente focadas em seu tratamento e em sua disponibilização, como a de tecnologia da informação (TI), voltada à sua manutenção, integração e geração, e a de controladoria, incumbida de seu tratamento, formatação e divulgação.

$A$ área de controladoria trabalha em conjunto com a de tecnologia da informação no planejamento e modelagem dos bancos de dados e dos sistemas de informações da organiza- ção, participando do processo de seleção de ferramentas tecnológicas, de acordo com a função estratégica de cada uma.

A partir disso, tornam-se relevantes os estudos sobre as ferramentas oferecidas para suprir a necessidade de controle e disponibilização do recurso informação para o apoio ao processo decisório. O estudo dos instrumentos oferecidos pela tecnologia da informação, em especial, estabelece uma nova relação de visualização do sistema empresa e do uso da informação. Em vez de visualizar as áreas funcionais como isolados sistemas de informações, pode-se visualizar a empresa de maneira integrada, através de relações dinâmicas e flexíveis. Para essa flexibilidade no gerenciamento sistêmico da organização, a literatura recente sobre o tema tem prescrito a utilização das ferramentas de Business Intelligence $(B I)$ conjuntamente com os demais sistemas, pois elas possibilitam a escalabilidade da informação definida pelo próprio usuário (BARBIERI, 2001).

Considerando esse contexto é que surgiu a questão que motivou a realização dessa pesquisa: como as ferramentas de Business Intelligence, providas pela tecnologia da informação, podem auxiliar a área de controladoria na sua função de prover informações confiáveis, úteis e tempestivas na forma requerida pelo processo decisório? A fim de responder a esse questionamento, o objetivo proposto foi: investigar a contribuição das ferramentas de TI, especificamente as de $B I$, para a área de controladoria exercer sua função de apoio ao processo decisório, evidenciandose no estudo realizado a situação precedente e posterior à implantação e uso das referidas ferramentas na empresa objeto deste trabalho.

\section{REFERENCIAL TEÓRICO}

\subsection{O ambiente da área de Controladoria}

$\mathrm{O}$ ambiente empresarial compreende uma rede de entidades cujas ações representam as variáveis ambientais que, por sua vez, dominam ou determinam a forma de atuação das organizações, formando um ciclo que passa a demandar dos gestores habilidades específicas para a condução de suas atividades, de forma a reposicionar a organização em seu meio, sempre que a preservação de seus objetivos reclamar essa postura. Tais variáveis podem ter as mais diversas conotações econômicas, político-legais, sociais e tecnológicas (WRIGHT; KROLL; PARNELL, 2000). Esse estudo destaca, entretanto, apenas as de natureza econômica e tecnológica devido à influência que exercem nas organizações. As variáveis econômicas são uma das determinantes para o nível de progresso das organizações, pois condições econômicas estáveis ou voláteis podem atuar como fatores estimuladores ou inibidores para a atuação $e$ prosperidade dos negócios e por essa razão, convertem-se em autênticos indicadores de prioridades para a empresa (HALL, 1984). Embora entre as forças econômicas, em um contexto amplo, existam elementos que criam oportunidades de lucro, devem-se observar as condições inerentes a essas variáveis, as quais cercam as organizações, melhoram e declinam à medida que elas reagem à situação de um dado momento (STEINER; MINER, 1981), tornando-se variáveis dignas de atenção por parte da administração de uma empresa.

A materialização e o alcance dos benefícios, ou inversamente dos malefícios, decorrentes das variáveis econômicas, entre outras, pode depender do volume e qualidade das informações que o gestor dispõe para a tomada de decisões (GUERREIRO, 1989). Nesse sentido, a área de controladoria tem a função de promover a eficácia das decisões, monitorando a execução dos objetivos estabelecidos, investigando e diagnosticando as razões para a ocorrência de eventuais desvios entre os resultados alcançados e os esperados, indicando as correções de rumo (ROEHL-ANDERSON; BRAGG, 1996).

A segunda variável destacada por esse estudo, a tecnológica, inclui novas abordagens para a produção de bens e 
serviços que podem ser facilitadas pelo surgimento de novas ferramentas de tecnologia da informação. As duas variáveis destacadas podem alterar a capacidade de geração de resultados econômicos da empresa, considerando-se a velocidade e a capacidade de processamento e conexão provenientes da $\mathrm{Tl}$, que podem aumentar substancialmente a eficiência da empresa como um todo, bem como a comunicação e a colaboração entre os seus usuários (O’BRIEN, 2004).

Isso se justifica à medida que a tecnologia da informação visa a fornecer aos administradores da empresa as informações demandadas por eles para atingir os objetivos de forma eficaz, baseando-se no entendimento de que o consumo de recursos, em sua plenitude, deve ter a função principal de produzir valor (MARTIN, 2002). Para atingilo, cabe à empresa determinar as necessidades do todo e organizar-se para a produção e a comercialização, estando ciente de que é uma tarefa contínua por se tratar de um ambiente dinâmico (TUNG, 1993). Baseia-se para isso em análises acuradas e, com o intuito de obter o desempenho ideal, o administrador da empresa tem como apoio a área de controladoria.

Essa área, por sua vez, atua compreendendo as operações globais da empresa, provendo informações e tendo o poder de comunicação aos gestores, sendo capaz de analisar as informações obtidas de diversas áreas, fornecendoas, por fim, em tempo hábil ao processo decisório, através de sistemas informatizados (ROEHL-ANDERSON; BRAGG, 1996; ECKERT; WILLSON, 1963).

\subsection{O controle organizacional sob a perspectiva da área de Controladoria}

O conceito de controle é tratado com freqüência pela literatura. Contudo, as formas empregadas para isso nem sempre permitem visualizarem-se as conexões existentes entre as diferentes situações em que ele é empregado. Nesse âmbito, é comum referir-se ao processo de gestão - o planejamento e a sua execução para se expressar um tipo de controle organizacional, enquanto o termo, também, é aplicado a outras situações, como, por exemplo: controle contábil, de custos, interno, e assim por diante. Dessa forma, a constatação é de que não se observam reflexões sobre os níveis de interdependência entre os diversos tipos possíveis de controle, tampouco sobre a importância do principal elemento que os integra: a informação, e dos atributos a ela inerentes, tais como: utilidade, tempestividade e fidedignidade.

Nesse contexto é que o conceito de controle organizacional se amplia e melhor explica as funções da área de controladoria, podendo ser, facilmente, entendido quando analisado sob a perspectiva de diferentes dimensões, que, para os fins deste estudo, são denominadas de gestão, de dados e informações e de controles e procedimentos internos.

A dimensão de controle de gestão representa a instância em que são tomadas as decisões que se traduzem nos resultados esperados pelos líderes da organização $e$ compreende todo o processo de gestão, em sua forma conhecida. Sua relação com o controle organizacional trans- cende a elaboração, a execução e o controle de planos. Ela alcança, na verdade, toda a metodologia de administração delineada pelo modelo de gestão da empresa com o propósito de levá-la aos resultados econômicos que satisfaçam os interesses dos donos do negócio e outros stakeholders. Nela pode-se contemplar as fases de planejamento, execução e controle. O planejamento estratégico, por seu turno, é a melhor combinação dos planos de cada área e global da empresa, orientando o desempenho de todos os seus gestores (LORANGE; VANCIL, 1986). O planejamento operacional pode ser considerado como a tradução e a quantificação daquilo que foi definido no planejamento estratégico, detalhando-se as ações e os resultados esperados. As fases seguintes englobam a execução dos planos e o controle entre o que foi planejado e o executado. Não obstante, essa dimensão depende de uma outra, a qual the garanta o suprimento das informações vitais para o acompanhamento e monitoramento do desempenho dos gestores e, por conseqüência, da empresa, que é a dimensão de controle de dados e informações.

A dimensão de dados e informações compreende o sistema de informações da empresa, necessário para, conforme Catelli, Pereira e Vasconcelos (2001), permitir que a área de controladoria exerça suas atividades de forma plena. Esse sistema incorpora todos os componentes do banco de dados físicos e econômicos da empresa, entre os quais o contábil, o de custos, o fiscal e o de ativo (HECKERT; WILLSON, 1963), que são tratados especificamente por este estudo.

O controle contábil acumula todos os registros dos eventos ou fatos oriundos das transações ocorridas na organização e delineia a forma como são registrados, traduzindo-os em informações usadas pela controladoria para evidenciar a situação real do negócio aos gestores (ATKINSON et al., 2000; TUNG, 1993). Segundo ludícibus (1997), o objetivo da contabilidade, tratada aqui como controle contábil, a qual acumula dados oriundos das demais áreas, pode ser resumido no fornecimento de informações econômicas para os vários usuários e o sistema deveria ter a capacidade para gerar relatórios especiais de acordo com as necessidades dos usuários.

O controle de custos abarca o planejamento e evolução do rendimento, a determinação dos preços, a valoração dos estoques e sua manutenção, e o controle de todos os gastos da organização (ROEHL-ANDERSON, 1996). Esse controle visa o gerenciamento de todos os aspectos que envolvem a modelagem e a alocação de custos por áreas, departamentos, centros de custos; a definição do método a ser adotado para cada apuração de custos; a análise custo-volume-lucro; a otimização no uso dos recursos; a avaliação contínua dos estoques e o auxílio na formação do preço de venda.

O controle de custos tem duas funções relevantes: "no auxílio ao controle dos eventos e na ajuda às tomadas de decisões". No que tange ao controle, sua mais importante missão é fornecer dados para o estabelecimento de padrões, orçamentos e outras formas de previsão e, num 
estágio seguinte, acompanhar o efetivamente acontecido comparando com os valores predefinidos. $\mathrm{Na}$ tomada de decisão, seu papel "consiste na alimentação de informações sobre valores que dizem respeito às conseqüências de curto e longo prazo referente a medidas de corte de produtos, fixação de preços de venda, opção de compra ou fabricação etc." (MARTINS, 2002, p.22).

Em se tratando de custos, podem-se destacar, também, os de natureza tributária, que são contemplados pelo controle fiscal, que, por sua vez, envolve a análise de condições que propiciem vantagens fiscais e redução legítima da carga de tributos, os quais impactam o resultado da organização. Nesse sentido, esse controle tem como uma de suas principais contribuições o planejamento tributário, por meio do qual é possível simular cenários e analisar o impacto dos aspectos tributários em toda a cadeia de valor da empresa.

Uma entidade possui uma estrutura patrimonial que respalda suas atividades e que sustenta sua existência. Assim, o controle de ativo torna-se um instrumento relevante para a gestão ao abranger critérios de imobilizações, depreciações, amortizações e exaustões, além das reavaliações que compõem o ativo fixo e demais operações relacionadas a caixa, recebimentos, estoques e investimentos. (HECKERT; WILLSON, 1963). Nesse ínterim, a área de controladoria utiliza-se de técnicas que levam à escolha da melhor alternativa de investimento em ativos, tais como tempo de recuperação do capital investido e custos e ganhos a eles associados (PADOVEZE, 2003). O controle de ativo, assim como os demais abordados até então, tem plena importância para a sistemática da empresa e para o adequado fluxo de informações entre as áreas e o processo decisório.
Sabe-se, porém, que para o sistema produzir informações úteis para o processo de gestão, ele deve trabalhar com dados acurados e íntegros, de forma a gerar informações confiáveis e tempestivas. Mas esses atributos não são garantidos apenas pela capacidade de processamento de dados da empresa. Os registros contábeis e outros podem refletir eventos que tenham ocorrido, todavia nada garante que contemplem tudo o que de fato ocorreu. Para isso, o entendimento do conceito de controle organizacional se amplia mais uma vez, ou seja, deve ser completo e seguro, o que conduz a uma terceira e última dimensão de controle: a de controles e procedimentos internos, cuja essência é garantir a integridade das informações sobre todos os eventos que dizem respeito às atividades da empresa, por meio de um conjunto de normas e procedimentos e de controles internos formais estabelecidos com o propósito de padronizar o comportamento administrativo, em todos os seus níveis. Busca proporcionar meios seguros de acompanhamento das ações dos membros organizacionais, possibilitando o rastreamento de cada transação ocorrida no âmbito da empresa. Uma visão integrada das dimensões de controle organizacional pode ser apreciada na Figura $1 \mathbf{0}$

Como se pode observar, a visão dimensional de controle é construída a partir do modelo de gestão da empresa, que está implícito ou explícito no comportamento de seus membros, em suas crenças individuais, nas decisões que tomam e na forma como planejam e executam suas atividades, bem como no tipo de domínio que exercem sobre seus resultados, conforme, entre outros autores, aponta Guerreiro (1989).

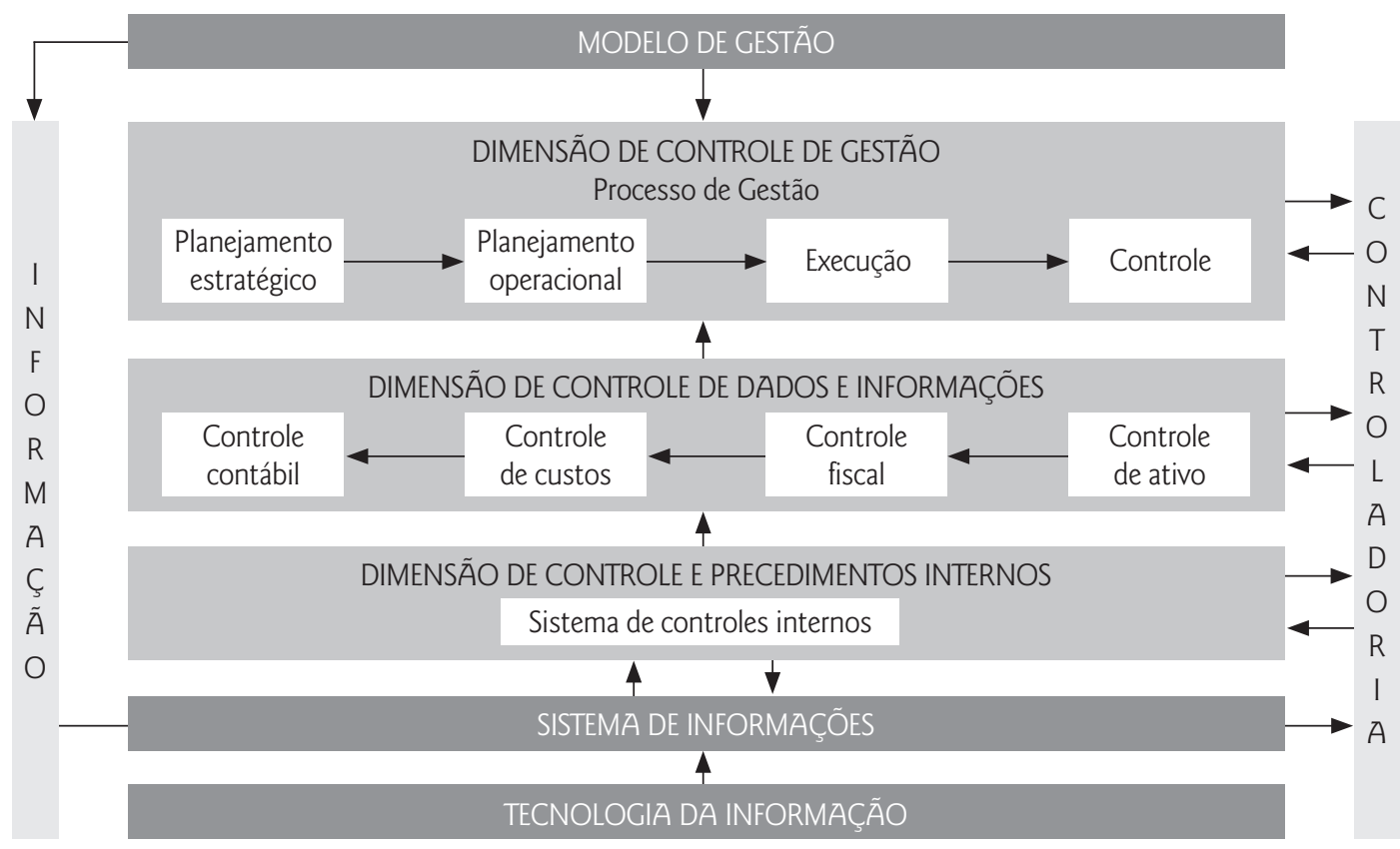

Fonte: Autores

Figura 1 | Dimensões de Controle 
O contorno das informações e a forma como elas fluem na organização são, do mesmo modo, determinados pelo modelo que orienta a sua gestão. Os gestores se comunicam e tomam decisões com base nas informações que possuem e, por isso, a empresa necessita controlá-las e torná-las acessíveis, confiáveis, tempestivas e adequadas para a tomada de decisões, por meio de sistemas apropriados de informações (CATELLI; PEREIRA; VASCONCELOS, 2001), que podem ter como apoio as ferramentas de tecnologia da informação, expostas a seguir.

\subsection{As ferramentas da área de Tecnologia da Informação (TI) como apoio à Controladoria}

Para atender às necessidades informacionais dos usuários, atualmente não se pode desconsiderar a tecnologia da informação e os seus respectivos recursos na utilização de sistemas de informações, e na conseqüente geração e transmissão do recurso informação (REZENDE; ABREU, 2003). Segundo a percepção de O'Brien (2004), a referida tecnologia pode auxiliar a organização a melhorar a eficiência de seus processos, a tomada de decisões e, com isso, fortalecer uma posição competitiva em seu mercado.

Dada a sua ascensão e relevância para as organizações, é importante ressaltar, conforme Keen (1993), entre outros autores, como Luftman, Lewis e Oldach (1993), que o conceito de tecnologia da informação é mais abrangente do que os sistemas de informações ou conjunto de hardware e software, ou seja, a TI envolve, além dos referidos sistemas, também os aspectos humanos, administrativos e organizacionais. Nessa linha, McGee e Prusak (1994) defendem a tese de que o recurso informação deve ser considerado o maior potencial de retorno às organizações e não somente a tecnologia como muitos autores defendem.

Como se percebe na Figura 1, a tecnologia da informação, considerando-se especialmente as ferramentas de BI, serve de apoio ao sistema existente na empresa, a partir de meios que permitam que os dados sejam armazenados de forma segura e transformados em informações úteis que devam ser comunicadas a qualquer tempo, de forma apropriada, a seus usuários. Para isso, a empresa tem o apoio do sistema de controle interno, que existe justamente para proporcionar a segurança dos registros, das informações e do próprio sistema informatizado.

Partindo do raciocínio de que a TI existe para flexibilizar e tornar dinâmicos os sistemas existentes e auxiliar na veiculação da informação entre os usuários que dela necessitem para realizar suas atividades, e que esses sistemas compõem a fonte de dados da empresa, analisam-se, a seguir, as ferramentas utilizadas na geração, no tratamento e na comunicação da informação: Business Intelligence.

\subsubsection{Business Intelligence}

As ferramentas de BI podem fornecer uma visão sistêmica do negócio e ajudar na distribuição uniforme dos dados entre os usuários, sendo seu objetivo principal transformar grandes quantidades de dados em informações de quali- dade para a tomada de decisões. Através delas, é possível cruzar dados, visualizar informações em várias dimensões e analisar os principais indicadores de desempenho empresarial (BATISTA, 2004). Essa facilidade, considerandose as características dessas ferramentas, pode contribuir diretamente para as funções da área de controladoria na obtenção, análise e comunicação do recurso informação aos gestores, além de permitir a essa área o estreito monitoramento das atividades da empresa como um todo.

Define-se BI como 'guarda-chuva' conceitual, visto que se dedica à captura de dados, informações e conhecimentos que permitam às empresas competirem com maior eficiência em uma abordagem evolutiva de modelagem de dados, capazes de promover a estruturação de informações em depósitos retrospectivos e históricos, permitindo sua modelagem por ferramentas analíticas. Seu conceito é abrangente e envolve todos os recursos necessários para o processamento e a disponibilização da informação ao usuário (BARBIERI, 2001).

Petrini, Pozzebon e Freitas (2004) pesquisaram a utilização de BI em grandes empresas brasileiras, através de uma técnica de survey. O resultado do estudo demonstrou que a utilização dessa ferramenta está ocorrendo há pouco mais de três anos em $73 \%$ das empresas pesquisadas. Os autores concluíram, também, que geralmente esse tipo de tecnologia é criada a partir de objetivos tecnológicos, sem levar em conta as necessidades informacionais: "há uma falta de foco na determinação de quais informações são mais relevantes para o negócio, ou até mesmo alinhar indicadores, que seriam incluídos no sistema com objetivos estratégicos" (PETRINI; POZZEBON; FREITAS, 2004, p. 12). Os autores identificaram que as empresas que utilizam algum tipo de ferramenta de $B I$, voltam sua atenção à metodologia de avaliação de desempenho e não à geração e flexibilização da informação.

Os componentes da ferramenta de gestão BI consistem no armazenamento de dados (data marts e data warehouse), na análise de informações (on line analytical processing - OLAP) e na mineração de dados (data mining). Veja o Quadro 10.

Uma empresa busca, através das ferramentas de $B I$, acessar e integrar indicadores de performance e tendência com diferentes graus de sintetização, capazes de auxiliá-la na condução do negócio. Nessa linha, McGeever (2000) apresenta uma outra visão do conceito de $B I$, referente ao tipo de informação segmentada que o gestor de um ramo de negócios procura. Fazendo uso de BI, o usuário pode formatar suas próprias informações, assim como pode conectá-las a outras a fim de obter uma melhor análise e um melhor resultado com o seu uso, ou seja, ele pode tornarse mais independente na busca de informações adequadas, não precisando de relatórios distintos.

A partir desse ferramental de $B I$ que facilita a geração e a comunicação do recurso informação aos usuários, a empresa pode ter flexibilização e dinamicidade em seus processos, podendo até mesmo suprir várias de suas deficiências e gerar um clima favorável ao seu contínuo desenvolvimento e ao seu pleno controle organizacional. 


\begin{tabular}{|c|c|c|c|}
\hline Data Warehouse (DW) & Data mart (DM) & OLAP & Data Mining \\
\hline $\begin{array}{l}\text { - Conjunto de dados } \\
\text { organizado por assunto e } \\
\text { integrado por data; } \\
\text { - Ferramenta capaz de } \\
\text { gerenciar grandes quanti- } \\
\text { dades de dados, modelan- } \\
\text { do-os para suprir as neces- } \\
\text { sidades dos executivos por } \\
\text { informações mais rápidas } \\
\text { sobre o desempenho da } \\
\text { empresa. }\end{array}$ & $\begin{array}{l}\text { - Subconjunto lógico e } \\
\text { físico do DW, suscetível às } \\
\text { consultas inesperadas dos } \\
\text { usuários; } \\
\text { - Estruturas moldadas com } \\
\text { dados encontrados no } \\
D W, \text { pertencentes a áreas } \\
\text { específicas na empresa, } \\
\text { como finanças, contabili- } \\
\text { dade, vendas etc. }\end{array}$ & $\begin{array}{l}\text { - Facilita o acesso do usuário } \\
\text { à base DW em que são } \\
\text { realizadas consultas pos- } \\
\text { sibilitando melhor análise } \\
\text { das informações; } \\
\text { - Capacidade atribuída aos } \\
\text { sistemas que permite aos } \\
\text { gestores examinarem e } \\
\text { manipularem interativa- } \\
\text { mente grandes quantida- } \\
\text { des de dados detalhados } \\
\text { e consolidados a partir de } \\
\text { diversas perspectivas. }\end{array}$ & $\begin{array}{l}\text { - Utiliza modelos sofistica- } \\
\text { dos para gerar modelos de } \\
\text { previsões; } \\
\text { - Exploração e análise, por } \\
\text { meios automáticos e semi- } \\
\text { automáticos, de grandes } \\
\text { quantidades de dados para } \\
\text { descobrir padrões e regras } \\
\text { significativos; } \\
\text { - Atende a fluxo de trabalho } \\
\text { imprevisível, e propicia a } \\
\text { análise em dados atuais e } \\
\text { históricos para determinar } \\
\text { futuras ações. }\end{array}$ \\
\hline
\end{tabular}

Fonte: Elaborado a partir de Barbieri (2001); Inmon (1997); Harrison (1998)

Quadro 1 Ferramentas de $\mathrm{BI}$

\section{MÉTODO DE PESQUISA}

O universo de pesquisa deste estudo foi uma empresa fabricante de sistemas de energia, selecionada por ser líder no mercado em que atua, e por ser um caso que pôde ser analisado sob o ângulo de todas as dimensões da pesquisa, isto é, possuía as áreas de TI e de controladoria em pleno funcionamento, as ferramentas de $B I$ implementadas e os respectivos resultados. Para confirmar se a empresa se adaptava ao estudo, enviou-se, inicialmente, um questionário ao gerente geral com questões que pudessem identificar essa adaptabilidade. Tratou-se de um caso único, pois se pretendeu analisar os procedimentos das áreas focadas, neste estudo, com profundidade e maior detalhamento.

O estudo envolveu uma pesquisa de campo, sendo desenvolvido o protocolo de estudo de caso com os procedimentos e as regras a serem seguidas pelo pesquisador ao utilizar o instrumento de pesquisa, com vistas a antecipar e corrigir possíveis problemas. As técnicas utilizadas para a coleta de dados foram entrevistas, pesquisa de documentação, registros em arquivos e observação direta. As entrevistas foram estruturadas por meio de questões abertas, visando entender e captar a perspectiva do entrevistado. Foram gravadas, transcritas e analisadas entre si, a fim de garantir maior confiabilidade à pesquisa e enriquecer o conteúdo de seu produto. Os depoimentos envolveram gestores das áreas de tecnologia da informação, controladoria, vendas, produção, especificamente a presidência e a gerência geral, pois caracterizam as áreas que sofreram, primeiramente, as mudanças e a implantação das ferramentas estudadas. O Quadro 20 explicita as evidências analisadas nesta pesquisa.

A pesquisa considerou os dados do período compreendido entre agosto de 2003 e dezembro de 2005, representando a fase precedente e a posterior à implementação das ferramentas de $\mathrm{Bl}$. Observou-se, durante a pesquisa de campo, o funcionamento e a rotina das áreas investigadas, sendo a análise dos dados realizada a partir de todas as evidências coletadas e estruturada de acordo com o propósito e o referencial teórico da pesquisa, objetivando extrair subsídios significantes para as conclusões deste estudo.

\section{ANÁLISE DOS RESULTADOS}

\subsection{Gerência Geral Corporativa}

a) Cenário precedente à implantação das ferramentas de $B I$

Observou-se, conforme depoimentos do gerente geral e do presidente da empresa, que para preservar sua continuidade de forma sustentável e obter os resultados econômicos desejados, ela precisou reestruturar-se. Isso envolveu a reformulação da forma de atuar de várias áreas, entre as quais a de controladoria, a de $\mathrm{Tl}$, a de vendas e a de produção, visando a uma adequada gestão dos custos variáveis e fixos, das despesas e dos preços de venda. A primeira área a ser estruturada foi a de controladoria, que, inicialmente exercia sua função de forma precária com o uso de planilhas eletrônicas que não permitiam a velocidade e o compartilhamento das informações, bem como uma apropriada interação com a área de TI. Isso ocorria devido 


\begin{tabular}{|c|c|c|}
\hline Áreas entrevistadas & Indicadores & Outros documentos, registros e observações \\
\hline \multicolumn{3}{|l|}{ Presidência } \\
\hline Gerência Geral & & Artigos publicados especializados do setor \\
\hline Controladoria & $\begin{array}{l}\text { Comparação dos fechamentos mensais } \\
\text { antes e após a implantação de } B I \text {. }\end{array}$ & $\begin{array}{l}\text { Organograma; } \\
\text { Observação das telas de consulta e geração de relató- } \\
\text { rios para monitoramento de desempenho das áreas e } \\
\text { global da empresa; } \\
\text { Uso de } B l \text {; } \\
\text { Detalhamento do fechamento mensal antes e depois } \\
\text { da implantação de } B l \text {; } \\
\text { Detalhamento da estrutura do pricing via } B l ; \\
\text { Observação da abertura dos custos por área, por centro } \\
\text { de custos, ordem de serviços e demais controles estru- } \\
\text { turados pela área de controladoria; } \\
\text { Rotinas de trabalho x utilização de } B I \text {. }\end{array}$ \\
\hline Tecnologia da Informação & $\begin{array}{l}\text { Comparação precedente e posterior à } \\
\text { implantação das ferramentas na área de } \\
\text { vendas. }\end{array}$ & $\begin{array}{l}\text { Organograma; } \\
\text { Observação das telas de consulta e geração de rela- } \\
\text { tórios para as áreas via } B I \text {, bem como do sistema e } \\
\text { ferramentas disponíveis. }\end{array}$ \\
\hline $\begin{array}{l}\text { Vendas de equipamentos } \\
\text { de pequeno porte }\end{array}$ & $\begin{array}{l}\text { Faturamento por linha de produto; } \\
\text { Quantidade de produtos vendidos; } \\
\text { Margem de contribuição por linha de } \\
\text { produto. }\end{array}$ & $\begin{array}{l}\text { Organograma; } \\
\text { Observação das telas de consulta e relatórios utilizados } \\
\text { pelas gestoras e analistas de vendas via } B I \text {, planilhas e } \\
\text { controles antes de } B \text { I feitos no excel e manualmente. }\end{array}$ \\
\hline $\begin{array}{l}\text { Vendas de equipamentos } \\
\text { de grande porte }\end{array}$ & $\begin{array}{l}\text { Faturamento por linha de produto; } \\
\text { Quantidade de produtos vendidos; } \\
\text { Margem de contribuição por linha de } \\
\text { produto. }\end{array}$ & $\begin{array}{l}\text { Organograma; } \\
\text { Observação das telas de consulta e relatórios utilizados } \\
\text { pelas gestoras e analistas de vendas via } B I \text {, planilhas e } \\
\text { controles antes de } B \text { I feitos no excel e manualmente. }\end{array}$ \\
\hline Produção & $\begin{array}{l}\text { Produtividade; } \\
\text { Horas extras realizadas; } \\
\text { Giro de estoque de produtos acabados e de } \\
\text { matéria-prima; } \\
\text { Atrasos de produção. }\end{array}$ & $\begin{array}{l}\text { Organograma; } \\
\text { Planilhas utilizadas antes da implantação de Bl; relató- } \\
\text { rios e telas de consulta via } B I .\end{array}$ \\
\hline
\end{tabular}

\section{Quadro 2 || Evidências analisadas na pesquisa}

ao fato de a Tl estar envolvida em customizações do sistema de informações utilizado, não raro para atender à área de vendas, que demandava diversos relatórios, e também pelo fato de a própria controladoria estar sempre sobrecarregada, compilando dados para auxiliar os gestores em suas tomadas de decisões.

b) cenário posterior à implantação das ferramentas de $B I$ Depois de analisadas as deficiências, a administração concluiu que não conseguiria o intento de dotar os gestores com as informações necessárias para a execução de suas atividades e para o monitoramento de desempenho, caso o problema maior - gestão da informação - não fosse superado. Assim, de forma planejada começou-se, tam- bém, a estruturação da área de TI, com investimentos em recursos humanos e tecnológicos, e das áreas de vendas e de produção.

\section{2 Área de Controladoria}

a) Cenário precedente à implantação das ferramentas de $B I$

Constatou-se que "não existiam informações que sustentassem tecnicamente as ações tomadas pela diretoria, que contava unicamente com o próprio espírito empreendedor e conhecimento de mercado", conforme depoimento do controller entrevistado. Cada área buscava fazer o melhor, porém sem saber se, ou como, estava afetando as outras e o resultado da empresa, tampouco tinha condi- 
ções de avaliar se estava executando adequadamente suas próprias tarefas.

A área de controladoria, por sua vez, não conseguia cumprir com eficácia o papel a ela destinado pelo comando executivo da empresa, gastando parte considerável de seu tempo para justificar valores que eram sistematicamente questionados pelos usuários das informações. O gestor da controladoria relatou que "antes da flexibilização da informação pelo $B I$, ele passava dias tabulando e formatando dados operacionais, em vez de cumprir com a função de provedor de informações à administração e de monitoramento das atividades operacionais".

Em 2003, o fechamento contábil do mês de janeiro estava ocorrendo em julho, o que tornava as informações intempestivas para a tomada de decisões e dificultava o trabalho da controladoria.

b) Cenário posterior à implantação das ferramentas de BI

Observou-se que a área de controladoria se estruturou, completamente, após a implantação e uso das ferramentas de $B I$ e do novo modelo de gestão adotado pela empresa.

As primeiras medidas tomadas consistiram em: implantação do custo integrado contábil, cuja realização, inicialmente, foi dificultada devido ao sistema até então utilizado ser pouco flexível e lento; na mudança de filosofia da gestão de tecnologia da informação, a qual anteriormente não possuía noção dos conceitos de controladoria, na implementação de ferramentas tecnológicas que possibilitassem a integração de todas as áreas e operações efetivadas na empresa; na descentralização das decisões; na disponibilização da informação e no constante monitoramento das operações com base confiável e, finalmente, na implantação de ferramentas de controle específicas da área de controladoria.

Em linhas gerais, constatou-se que a implantação das ferramentas de $B I$ trouxe diversos benefícios para a empresa. Além de permitir maior visibilidade sobre suas operações, através de informações diárias, resolveu um dos problemas que impedia a área de cumprir a sua missão, que foi o tempo que passou a ter para monitorar a operação, em vez de apenas se dedicar à prestação de informações para as outras áreas. Com isso, os custos da organização passaram a ser examinados com maior acuidade e em intervalos menores de tempo, possibilitando-se a correção de desvios entre os resultados realizados e os planejados em base diária.

Outro ponto que merece destaque foi o efeito do uso das ferramentas sobre a rotina da contabilidade, que passou a melhor apurar e acompanhar os saldos de eventos como: obsolescência de estoque, inadimplência, fretes, comissões, bônus, gastos com desenvolvimento de produtos e transferências de receitas e despesas entre os departamentos. Adicionalmente, a utilização dos cubos OLAP, aplicados para o desmembramento do balancete em áreas de gestão da empresa, ampliou a possibilidade de controle sobre cada área de atividade, pois, ao utilizar o serviço de outra, essas passaram a medir o impacto econômico que a relação cliente-fornecedor interno sofre em decorrência das decisões tomadas pelos gestores. Além disso, houve um refinamento das bases de rateio utilizadas pela contabilidade para a alocação de custos e despesas fixos. "Com o uso das ferramentas de $B I$ uma técnica conhecida como target costing, antes impraticável, tornou-se viável, mostrando-se, também, compensadora, sob a perspectiva de redução de custos", conforme mostrou a entrevista com o controller. Pôde-se, ainda, implementar a ferramenta Pricing, sistema de precificação, que antes não era possível.

Em relação à contribuição das ferramentas $B I$ para o resultado da empresa, o controller relatou:

Posteriormente à aplicação das ferramentas de BI, conseguimos mensurar com detalhe os resultados gerados por cada departamento, atividade, cliente, vendedor, gerente, produto ou segmento da empresa. Diante disso, pudemos tomar as decisões para corrigir ou mudar os caminhos que a empresa estava atuando, aumentando consideravelmente a sua margem de contribuição e seu resultado operacional e econômico.

\section{3 Área de Tecnologia da Informação}

$A$ área de tecnologia da informação da organização objeto deste estudo foi considerada pela sua administração como um dos elementos que facilitou o processo de mudança de seu modelo de gestão e a obtenção de melhores resultados econômicos.

a) Cenário precedente à implantação das ferramentas de $B I$

Havia a necessidade constante e maciça de relatórios que geravam gargalos na área de TI. Isso porque os profissionais dessa área aplicavam boa parte de seu tempo no desenvolvimento, customização e validação de relatórios para atender a solicitações das outras, que eram usados, muitas vezes, para uma única decisão ou simplesmente para a averiguação de determinadas situações pontuais. Como conseqüência, a TI não podia atender a demanda de todas as outras áreas, estimulando-as com isso, indiretamente, a criarem para si seu próprio arcabouço de inteligência de informação.

As áreas estavam repletas de pessoas que tinham por função garimpar os dados nos vários relatórios do sistema integrado utilizado e formatá-los, usando-se, para tanto, planilhas eletrônicas de dados. Como ilustração, o departamento de vendas, somando-se todas as horas de garimpagem de dados, aplicava o tempo equivalente ao trabalho de pelo menos duas pessoas nessa atividade. Esses dados eram retirados do sistema de forma não integrada, formando várias 'ilhas' de informações, que nem sempre eram consistentes entre si, causando uma grande desconfiança dos usuários na área de tecnologia da informação e no próprio sistema, conforme entrevista com o gestor de TI da empresa.

Esse processo de geração de relatórios em quantidade e, por vezes, desnecessários foi considerado pelo mencionado gestor como improdutivo à medida que:

- A empresa perdia o controle sobre a quantidade e os locais de geração das informações;

- A área de TI precisava dedicar tempo para esses desenvolvimentos; 
- Toda nova implantação, mesmo que de simples relatórios ou processos, possuía níveis de complexidade. Em muitos casos essa complexidade é subestimada causando a geração de informações erradas ou inconsistentes, afetando, por conseqüência, um dos principais atributos que deve ser intrínseco a ela: sua qualidade;

- Ao se desenvolverem relatórios guiados pelos impulsos dos usuários, perdia-se a visão global dos processos da empresa, implicando em indesejáveis riscos sistêmicos;

- Informações inconsistentes geram descrédito tanto para a área solicitante quanto para a área solicitada, afetando, também, a área de controladoria, que é usualmente associada à qualidade das informações.

b) Cenário posterior à implantação das ferramentas de $B I$ As primeiras ferramentas utilizadas para a implantação de $B I$ foram softwares com tecnologia OLAP e softwares de geração de relatórios (querys), focando a área de vendas, a área de controladoria e, como decorrência, a de produção.

Essa tecnologia trouxe para a área de TI organização e conhecimento sistêmico das correlações entre os vários tipos de dados constantes do sistema integrado utilizado pela empresa. Isso poupou tempo na geração de novos relatórios. Os usuários passaram a ter facilidade de visualização das informações em diversos formatos, possibilitandolhes que avaliassem, constantemente, o resultado de suas decisões, sem a intervenção da área de TI nesse processo.

A informação transmitida deixou de ser estática e sua formatação e nível de detalhes passou a ser controlada pelo próprio usuário. Com isso, houve uma redução considerável no número de solicitações de serviços à área de Tl e o resultado foi uma maior consistência nas informações, bem como na velocidade com que passaram a ser disponibilizadas. Assim, verificou-se um expressivo ganho de produtividade, tanto para a área solicitante quanto para a de TI.

Do ponto de vista do gestor de TI, os principais benefícios com a implantação das ferramentas foram: a redução de retrabalho por erros de informações ou de definições, uma melhor compreensão global dos processos da empresa, a diminuição da quantidade de relatórios desenvolvidos, a integração das áreas organizacionais, proporcionada pela agilidade e coerência na informação e no seu formato modelado pelo próprio usuário.

c) A seguir, exemplo de melhorias usufruídas pela área de TI.

\begin{tabular}{|c|c|c|}
\hline Variáveis & Antes das ferramentas de $B I$ & Após as ferramentas de $B I$ \\
\hline Quantidade de Relatórios / Consultas & 7 & 1 \\
\hline Informações conseguidas com os relatórios / consultas & $\begin{array}{l}\text { - Quantidade em Pedido } \\
\text { o Por Produto } \\
\text { o Por Vendedor } \\
\text { o Por Região } \\
\text { - Valor em Pedido } \\
\text { o Por Produto } \\
\text { o Por Vendedor } \\
\text { o Por Região } \\
\text { - Valor Faturado } \\
\text { o Por Produto } \\
\text { o Por Vendedor } \\
\text { O Por Região } \\
\text { - Saldo em Estoque }\end{array}$ & $\begin{array}{l}\text { Todas as informações podem } \\
\text { ser visualizadas por: } \\
\text { - } \quad \text { Produto } \\
\text { - } \quad \text { Família Produto } \\
\text { - } \quad \text { Estado } \\
\text { - Município } \\
\text { - Cliente } \\
\text { - Linha de Negócio } \\
\text { - Vendedor } \\
\text { - Supervisor } \\
\text { As visualizações podem ser } \\
\text { combinadas entre si de forma } \\
\text { que gerem, por exemplo: } \\
\text { produtos por Estado, clientes } \\
\text { por linha de negócio; formando } \\
40.320 \text { combinações possíveis. } \\
\text { Para essas combinações é possí- } \\
\text { vel medir: Quantidade; } \\
\text { - Faturamento Bruto } \\
\text { - Faturamento Líquido } \\
\text { - Margem de Contribuição } \\
\text { - Impostos }\end{array}$ \\
\hline Tempo despendido na extração das informações & 160 horas/mês & On-line \\
\hline Confiabilidade da informação & Baixa & Alta \\
\hline
\end{tabular}




\section{4 Área de Vendas}

a) Cenário precedente à implantação das ferramentas de $B I$

Um dos pontos frágeis detectados na área de vendas foi o fato de que não havia qualquer controle sobre as margens de contribuição praticadas quando os negócios eram efetivados por representantes, os quais recebiam comissões mesmo se as mencionadas margens fossem negativas.

O depoimento de uma das gestoras de vendas entrevistada indicou que "a equipe trabalhava com muita garra, buscando negociações incessantemente, sem qualquer parâmetro que a permitisse avaliar a qualidade do negócio que realizava". Às vezes, dois vendedores contatavam o mesmo cliente, e, sem o saber, efetivava a negociação aquele que oferecesse o melhor preço. "Como não tínhamos controle de resultado por clientes, não trabalhávamos com margem e a venda era puramente quantitativa, e não qualitativa; o que realmente importava era o pedido", ressaltou ela.

Para cada informação julgada necessária, a área de vendas solicitava à de tecnologia da informação um relatório específico, como por exemplo: quanto se vendeu em um determinado período, pedidos em carteira, pedidos faturados, pedidos faturados e não entregues, pedidos rejeitados, qual era a participação do representante em determinada região, etc. Não era possível controlar e saber a situação econômica real dos negócios realizados, tampouco se trabalhava com o conceito de margem de contribuição.

Para melhorar essa situação, foi preciso modelar o sistema para que ele propiciasse informações tempestivas e acuradas que permitissem a cada componente da equipe a simulação do resultado de cada negócio potencial, adotando-se na empresa, assim, as ferramentas tecnológicas de Business Intelligence.

b) Cenário posterior à implantação das ferramentas de $\mathrm{BI}$

As informações passaram a ser acessadas facilmente pelo próprio usuário, permitindo-Ihes visualizarem as atividades globais de vendas. Obteve-se rapidez e condições de se estudarem os resultados por clientes, avaliar o potencial econômico de cada negociação antes de sua efetivação. "Enfim, maior visibilidade sobre as variáveis que envolvem as transações de vendas, durante suas ocorrências", conforme entrevista.

Implementou-se um relatório denominado "acompanhamento de vendas", no qual cada vendedor, durante as consultas telefônicas de clientes, passou a simular o mix de produtos que preservasse a margem planejada e as suas próprias metas, pois alguns produtos têm margem baixa, ao contrário de outros. Assim, quando um cliente faz uma consulta para a compra de um produto de baixo valor agregado, o vendedor utiliza a ferramenta para balancear o mix até o ponto em que a margem média atinja aquela planejada. Também, foi implantado o Sales Forecast, que contribui diretamente para a programação da produção, melhorando, assim, seu desempenho.

Pôde-se constatar que, por meio da flexibilização da informação, o resultado operacional dessa área sofreu me-
Ihorias e, conseqüentemente, a empresa vem experimentando um consistente aumento em seu faturamento. $\mathrm{O}$ crescimento observado foi de cerca de $14 \%$ no primeiro trimestre de 2005, 23\% no segundo, $18 \%$ no terceiro e $30 \%$ no quarto, comparados a igual período do ano anterior.

\section{5 Área de Produção}

a) Cenário precedente à implantação das ferramentas de $B I$

Entre as áreas contempladas por esta pesquisa a de produção era aquela que menos utilizava as ferramentas de $B I$, pelo menos aquela em que a eficácia dessas ferramentas não pôde ser comprovada de forma plena, pois parte delas ainda estava em fase de implantação.

Essa área promovia, semanalmente, reuniões com as áreas de vendas, compras e de programação para tentar sincronizar os itens e as quantidades de bens que eram produzidos com aquilo que seria vendido. Essa prática era adotada porque, em função da programação de produção ser feita com base em médias históricas de bens produzidos, era comum produzirem-se itens que não estavam sendo demandados pelo mercado em um determinado momento.

Para serem achados espaços para se produzirem todos os bens, os necessários e os desnecessários para o momento, as horas extras dos funcionários da produção eram a solução, assim como a empresa convivia com o problema de constantes mudanças de setup de máquinas para se produzirem diferentes itens. "As atividades de produção não eram fáceis", observou o gestor da área, "ao ponto em que se tinha como meta uma variação máxima de $20 \%$ entre as quantidades e itens produzidos e aquelas que efetivamente seriam vendidas em condições normais".

b) Cenário posterior à implantação das ferramentas de BI

Essa área passou a ter as informações que the possibilitaram prever com maior precisão as quantidades que se esperava vender, através do Sales forecast. Com isso, a variação entre o que se produzia e aquilo que se vendia, anteriormente superior a $20 \%$, caiu a níveis bastante inferiores, algo em torno de 5\%, conforme evidências pesquisadas. Noutras palavras, a área de produção passou a operar com maior estabilidade. Uma outra conseqüência benéfica da implementação de tais ferramentas foi a diminuição dos estoques de giro lento, facultando à empresa melhorar a qualidade de seus estoques de produtos acabados, investindo-se na produção daqueles itens cujas vendas seriam mais prováveis e cujo giro fosse mais rápido.

O aumento de produtividade da fábrica, conforme Gráfico $1 \boldsymbol{\theta}$, passou a ser constante, o que refletiu o amadurecimento da utilização das ferramentas de $B I$, materializado pela melhoria da qualidade das informações, com conseqüências favoráveis diretas no resultado da organização.

Por meio do constante monitoramento das atividades foi possível cumprir com as metas de produção, eliminando-se os atrasos até então observados. A empresa passou, também, a apresentar uma tendência de redução do custo com horas extras, pois com o acesso tempestivo à infor- 


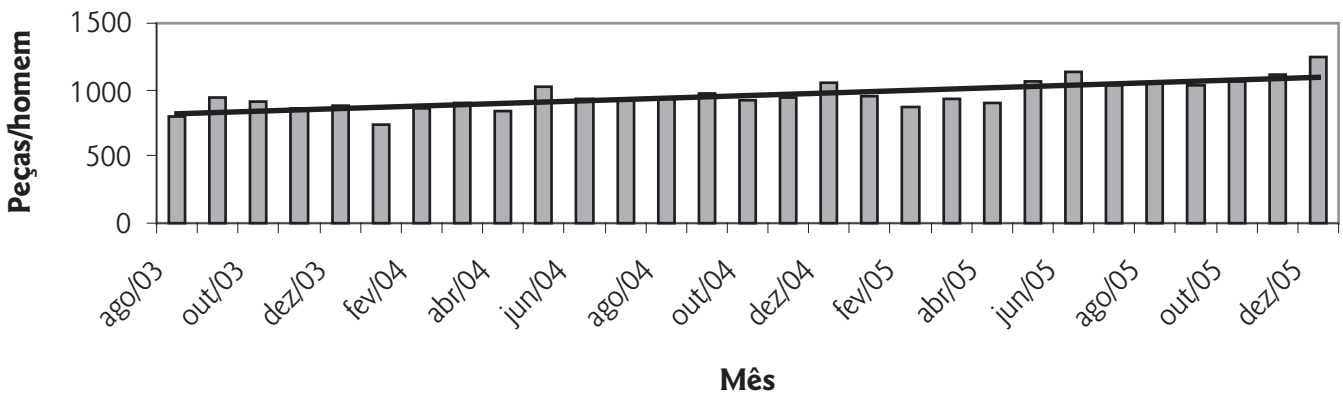

Fonte: Relatório de Fechamento Mensal de Produção

Gráfico 1 ॥ Produtividade

mação passou a ser possível o monitoramento da operação e a correção de falhas que ocorriam. Segundo o gestor, atualmente "só são feitas horas extras nos casos em que precisamos atender à demanda da área de vendas, que não tenha conseguido negociar com o cliente de outra forma".

\subsection{Reflexo econômico nas atividades globais da empresa}

Essa seção tem como finalidade analisar os indicadores globais relacionados a valores contidos nas demonstrações do resultado do exercício do período abrangido pela pesquisa: 2003, 2004 e 2005. Os reflexos no resultado econômico da empresa, decorrentes das medidas tomadas, podem ser percebidos na análise permitida pelos dados contidos no Gráfico $2 \mathbf{0}$.

Como se observa, as vendas líquidas trimestrais cresceram, significativamente, movendo-se de um patamar em torno de 19 milhões no início do quarto trimestre de 2004 para algo ao redor de 25 milhões no final do quarto trimestre de 2005, isto é, um crescimento consistente de aproximados $33 \%$ no período.

O gerente geral da organização ponderou que "o êxito alcançado nos últimos meses não se deve especificamente à implantação das ferramentas de BI. Outras medidas foram tomadas e seus impactos também estão refletidos nos resultados alcançados". Entre elas, pontuou o gestor, "talvez a principal tenha sido a descentralização das decisões da área comercial e a eliminação do excesso de burocracia até então marca registrada da área". Acrescentou, "logicamente, para que essas decisões fossem tomadas, seria necessário que a informação consumida pela área tivesse credibilidade, acessibilidade e disponibilidade". Nesse particular, não poderiam ter sido tomadas caso não fossem as ferramentas de BI utilizadas e, principalmente, o envolvimento das áreas de controladoria e de tecnologia da informação para conferir às informações os atributos julgados necessários, observou o gestor.

Com relação aos benefícios que a implantação das ferramentas de $B I$ trouxeram para os custos variáveis da empresa, como se observa nos dados apresentados no Gráfico 30 , foram significativos, sendo que se relacionaram basicamente a dois fatores: a um melhor controle das horas extras dos funcionários indiretos, tais como: de almoxarifado, supervisão de fábrica, de manutenção e outras áreas de apoio à produção, exercido pelas áreas de controladoria e de produção, e ao aumento da produtividade da área de produção, conforme já destacado.

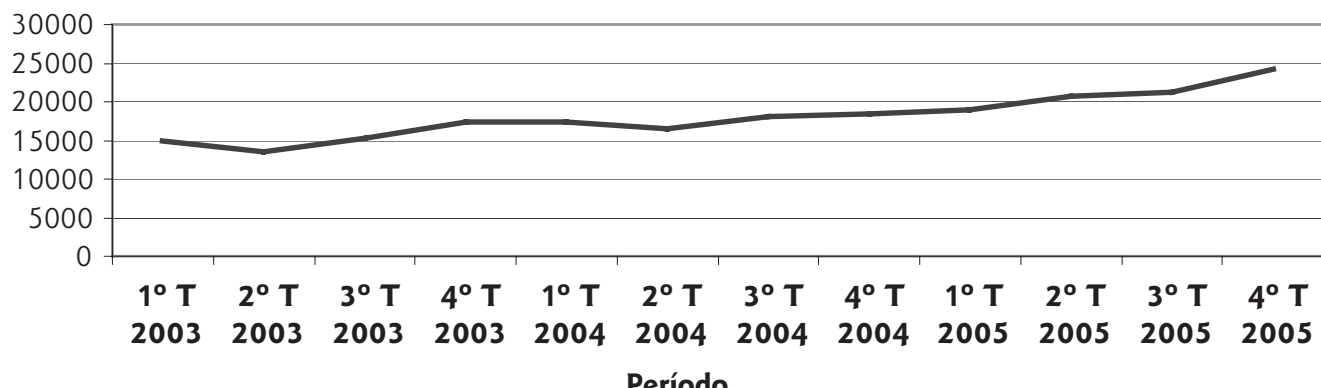

Fonte: Elaborado a partir das DREs fornecidas pela empresa

Gráfico 2

Evolução da receita líquida de vendas 
Proporcionalidade dos custos variáveis em relação à receita líquida

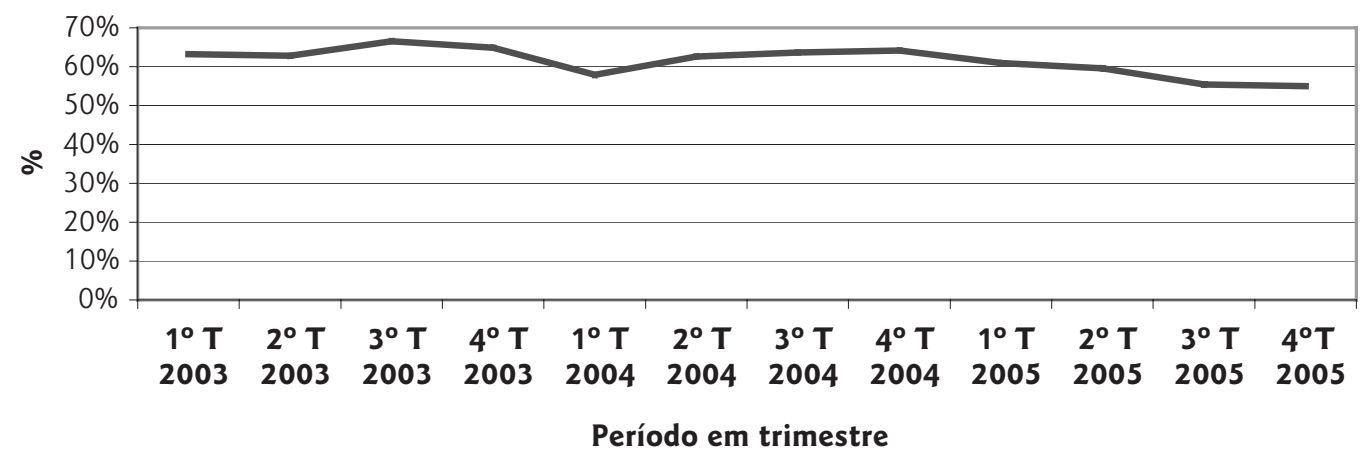

Fonte: Elaborado a partir das DREs fornecidas pela empresa

Gráfico 3 - Custos variáveis

Enfatize-se a participação da controladoria nos benefícios alcançados na gestão do custeio variável, por meio do monitoramento diário dos fatores de produção, o que se tornou possível dada a atual estrutura de informações que possibilita a ambas as áreas o controle dos fatores produtivos através do compartilhamento dessas informações geradas pelas ferramentas de $B I$.

Os gastos gerais de fabricação (GGF) incluem a mãode-obra indireta relacionada às áreas de controle de qualidade, almoxarifado, manutenção da fábrica, engenharia de testes, entre outras, e demais gastos com a fábrica. Podese observar, no Gráfico $4 \mathbf{0}$, que a partir de 2004 os gastos sofreram uma queda progressiva. Nesse tocante, os valores decresceram em média $7 \%$ durante os trimestres em relação às vendas do mesmo período, ou seja, no $1^{\circ}$ trimestre de 2003, os gastos gerais de fabricação correspondiam a $18 \%$ da receita líquida de vendas, enquanto no $4^{\circ}$ trimestre de 2005 espelharam $11 \%$ da receita.

Esse resultado positivo pode ser atribuído ao monitoramento que se passou a fazer dos recursos consumidos e do bom desempenho da área produtiva. Os relatos do controller mostraram que, com a implantação das ferramentas de $B I$ e a conseqüente flexibilidade na informação, a con- troladoria passou a acompanhar os custos de produção e sua estrutura. Com essa facilidade, atualmente 0 analista técnico de custos, juntamente com o controller, consegue controlar os gastos com mão-de-obra direta e indireta e os demais usando como parâmetro os valores que foram orçados. Se houver algum desvio, as medidas a serem tomadas são discutidas com o gestor da produção e, então, executadas, instantaneamente.

Além disso, existia na empresa o problema de uma "fadiga elevada", classificada pelo gestor da produção como as paradas do funcionário durante o trabalho. Por meio do constante monitoramento das atividades produtivas, pelo gerente da área de produção em conjunto com o controller, foi possível diminuí-la, uma vez que se passou a cumprir metas de produção, com vistas a não atrasar a entrega dos produtos. Minimizando-se o problema das paradas desnecessárias de funcionários, também se podem perceber os respectivos reflexos econômicos, isto é, o impacto da redução dos gastos de fabricação em relação à receita.

Os dados constantes do Gráfico $5 \bullet$ mostram um aumento sensível na margem de contribuição global da empresa, partindo de $19 \%$ no primeiro trimestre de 2003 e chegando a $33 \%$ no $4^{\circ}$ trimestre de 2005 , representando

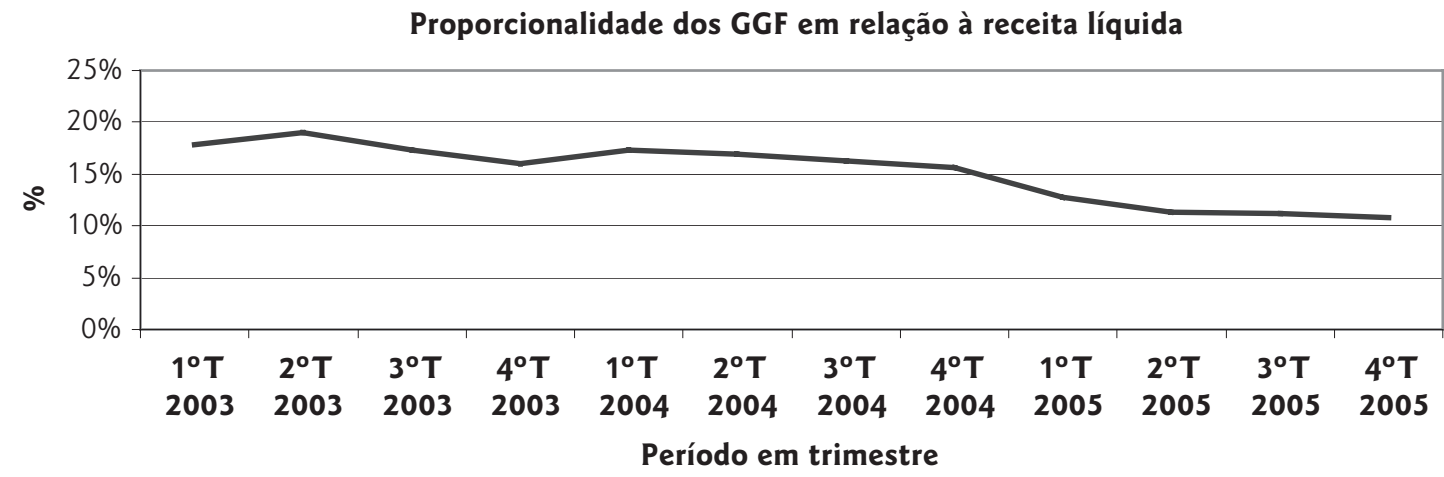

Fonte: Elaborado a partir das DREs fornecidas pela empresa

Gráfico 4 ॥ Gastos Gerais de Fabricação 


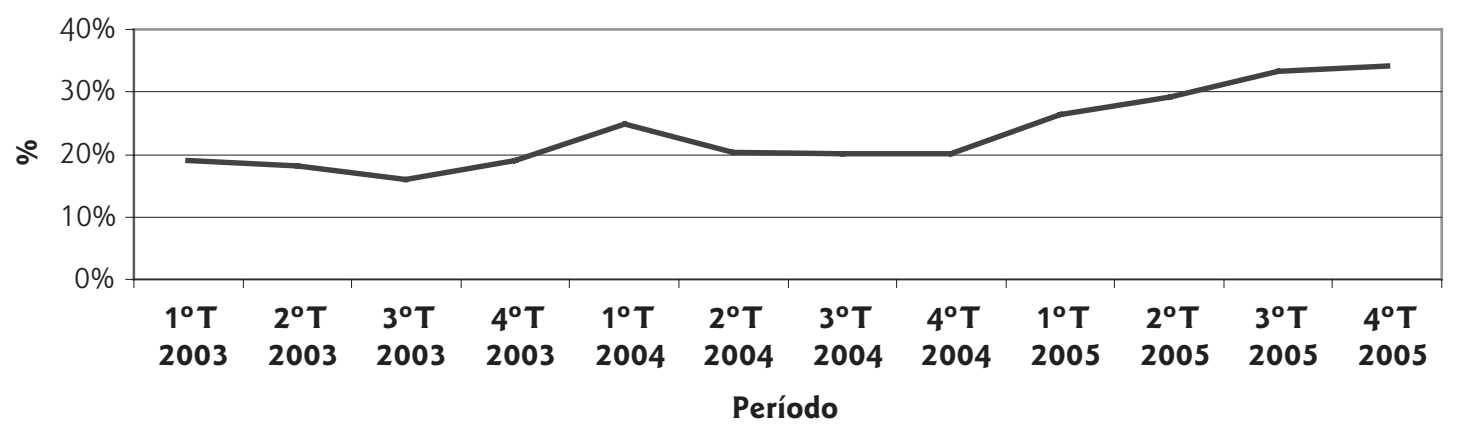

Fonte: Elaborado a partir das DREs fornecidas pela empresa

Gráfico 5 - Margem de Contribuição

uma mudança do patamar de aproximadamente $\mathrm{R} \$ 3 \mathrm{mi}$ lhões para $\mathrm{R} \$ 9$ milhões nesse período.

O aumento de margem tornou-se possível, entre outros fatores, a partir da correção da postura de alguns representantes comerciais da empresa, que praticavam preços baixos a ponto de produzirem margens negativas, sem prejuízo de suas comissões. O fato, antes do detaIhamento das informações das vendas por produto e por representante, já havia sido identificado pela área de controladoria que, entretanto não possuía mecanismos que Ihe permitissem atuar junto à área de vendas de forma preventiva, pois as informações necessárias para o diagnóstico da situação não eram completas. Com a implementação das ferramentas de BI, a área de controladoria pôde atuar junto à de vendas, no sentido de treinar seus integrantes conceitualmente, de forma que eles próprios pudessem identificar o problema à medida que ele ocorresse, evitando-se a efetivação de negócios indesejáveis, de acordo com a situação comentada.

Um outro aspecto relevante que também contribui para a melhoria da margem de contribuição foi um módulo de simulação, incluído entre as ferramentas de BI implementadas, que permitiu aos profissionais da área comercial a simulação do mix de produtos que possibilitasse a obtenção de margens melhores. Assim, as vendas passaram a ser mais qualitativas, o que proporcionou os resultados até então colhidos.

De forma geral, o significativo crescimento nas margens de contribuição demonstra a importância que a flexibilização nos processos organizacionais, propiciada pela disponibilização de informações adequadamente formatadas, e no tempo oportuno, teve no resultado global da organização.

$O$ resultado das melhorias constatadas e relatadas por essa pesquisa se refletem no Gráfico $6 \boldsymbol{0}$, o qual evidencia um aumento representativo do lucro operacional. No primeiro trimestre de 2003, a empresa operava com um prejuízo de $10 \%$ em relação ao faturamento líquido e no último trimestre analisado por este estudo apresentou 15\% de lucro. Um dos principais motivos para a empresa ter um resultado negativo até dezembro de 2003 era a ausência de informações com que a área de vendas trabalhava e a falta de controle e acompanhamento do planejamento comparado ao seu resultado realizado. De 2004 em diante, notase que o resultado se manteve sempre positivo.

A partir de janeiro de 2005, observa-se uma tendência mais acentuada de evolução do resultado operacional o que levou ao seu aumento de 1\%, em relação à receita líquida, no final de 2004, para $12 \%$ no último trimestre analisado por essa pesquisa. Nesse mesmo período, as evidências indicaram que as ferramentas de $B I$ já estavam sendo plena-

Lucro operacional como um percentual da receita líquida

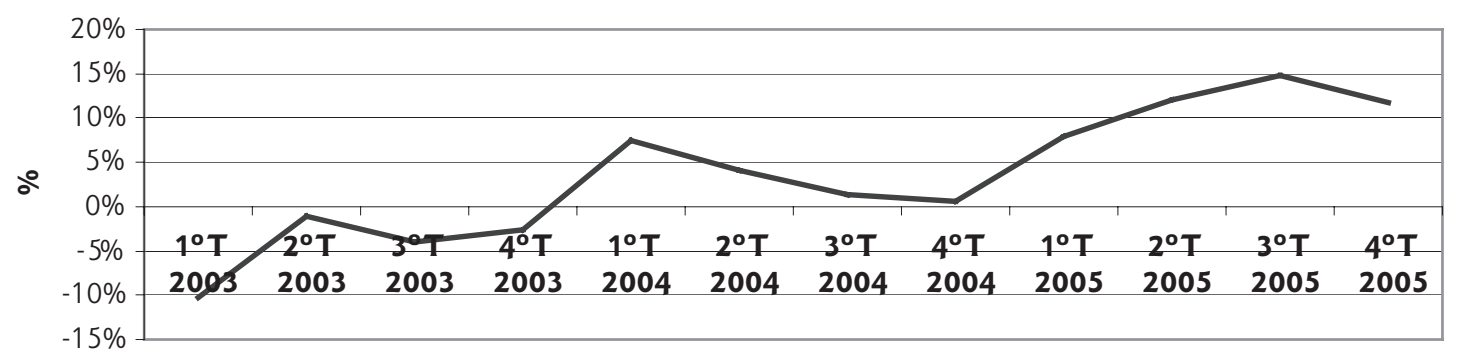

Período

Fonte: Elaborado a partir das DREs fornecidas pela empresa 
mente utilizadas e, com isso, a repercussão das melhorias na formatação e acesso da informação passou a ser visualizada não só nos resultados de cada área da empresa, mas, também, em seu resultado global, o que contribuiu para que essa pesquisa atingisse os seus objetivos e pudesse levar às conclusões destacadas na próxima seção.

\section{CONCLUSÕES}

Tendo em vista a relevância do recurso informação, torna-se importante que as empresas destinem atenção especial ao seu formato e à forma em que ele é obtido. Nesse sentido, áreas como a de tecnologia da informação e de controladoria atuam em sinergia com o objetivo principal de prover informações adequadas e comunicá-las de forma eficaz aos tomadores de decisões que propulsionam ou não o desempenho da organização. Para facilitar o processo de sua geração, disponibilização e comunicação, assim como o melhoramento interno das áreas organizacionais e o desempenho, principalmente da área de controladoria, é que surgiram as ferramentas de Business Intelligence, que têm o desígnio de tornar dinâmico e flexível o uso das informações, formatadas e manuseadas pelo próprio usuário.

Nesse âmbito, este estudo teve como propósito geral investigar a contribuição das ferramentas de Business Intelligence $(B I)$ para a área de controladoria exercer sua função de apoio junto ao processo decisório.

Pôde-se constatar que as ferramentas de BI proporcionaram à área de controladoria da empresa objeto do estudo, a estruturação de diversos controles que antes não existiam, o acompanhamento tempestivo do desempenho das áreas, o provimento instantâneo de informações aos gestores da empresa. A área de tecnologia da informação, por seu turno, passou a gerenciar a informação e os recursos tecnológicos disponibilizados, e não mais passou o tempo compilando dados e estruturando relatórios, por vezes desnecessários e inoportunos. O benefício, possibilitado pelas ferramentas de $B I$, estendeu-se às áreas operacionais estudadas por essa pesquisa: de vendas e de produção, que puderam melhorar suas atividades internas, contribuindo para a melhoria do funcionamento sistêmico da organização.

Através das evidências analisadas - entrevistas, documentos, registros em arquivos e observação direta - notouse que com a utilização das ferramentas de $B I$ a empresa obteve um considerável aumento no desempenho operacional. A reestruturação interna, proveniente do novo modelo de gestão experimentado pela empresa desde 2004, só foi possível por meio da flexibilização e disponibilização em tempo real do recurso informação, pela atuação da área de TI como gestora da informação e da controladoria como apoiadora direta do processo decisório, devidamente embasados nas ferramentas de BI.

É oportuno destacar que não se pode afirmar que as ferramentas de BI por si só aumentaram os resultados econômicos da organização, no entanto, é possível afirmar que o recurso informação é essencial e que necessita ser flexível e tempestivo, o que leva à constatação de que as referidas ferramentas contribuem, consideravelmente, para a harmonização interna da organização, para o funcionamento de todas as áreas em prol do objetivo definido pela alta administração e disponibilizam informações consistentes e confiáveis para os gestores tomarem decisões inequívocas. Finalmente, dadas as evidências obtidas nesta pesquisa, conclui-se que as ferramentas de $B I$ podem auxiliar a controladoria na sua função de prover informações confiáveis, úteis e tempestivas requeridas pelo processo decisório, por meio de sua flexibilização e dinamicidade.

\section{Referências Bibliográficas}

ATKINSON, Anthony; BANKER, Rajiv D; KAPLAN, Robert S; YOUNG, Mark. Contabilidade gerencial. São Paulo: Atlas, 2000.

BARBIERI, C. BI - Business Intelligence: Modelagem e Tecnologia. Rio de Janeiro: Axcel Books, 2001.

BATISTA E. O. Sistemas de informação. São Paulo: Saraiva, 2004.

CATELLI, A.; PEREIRA, C.; VASCONCELOS, M. Processo de Gestão e Sistemas de Informações gerenciais. In: Controladoria: uma abordagem da gestão econômica. Armando Catelli (coordenador). São Paulo: Atlas, 2001.

GUERREIRO, Reinaldo. Modelo conceitual de sistema de informação de gestão econômica: uma contribuição à teoria da comunicação da contabilidade. Tese 1980 (Doutorado em Controladoria e Contabilidade). Faculdade de Economia, Administração e Contabilidade. Universidade de São Paulo, São Paulo, 1989.

HALL, Richard. Organizações, estrutura e processos. Rio de Janeiro: Prentice-Hall, 1984.

HARRISON, T.H. Intranet Data Warehouse. São Paulo: Berkeley, 1998.

HECKERT, J.Brooks; WILLSON, James D. Controllership. New York: The Ronald Press Copany, 1963.

INMON, W.H. Como construir o Data Warehouse. Rio de Janeiro: Campus, 1997.

IUDÍCIBUS, Sérgio de; MARTINS, Eliseu; GELBCKE, Ernesto Rubens. Manual de contabilidade das sociedades por ações: aplicável às demais sociedades. 6. ed. São Paulo: Atlas, 2003. 
KEEN, P.G.W. Information technology and the management theory: the fusion map. IBM System Journal, v.32, n.1, p.17-38, 1993.

LORANGE, Peter; VANCIL, Richard F. Como Projetar um Sistema de Planejamento Estratégico. São Paulo: Nova Cultura Ltda., 1986.

LUFTMAN, J.N.; LEWIS, P.R; OLDACH, S.H. Transforming the enterprise: the alignment of business and information technology strategies. IBM Systems Journal, v. 32, n.1, p.198-221, 1993.

MARTIN, Nilton Cano. Da contabilidade à controladoria: a evolução necessária. Revista Contabilidade \& Finanças, São Paulo, n.28, p.7-28, jan/abr. 2002.

MARTINS, Eliseu. Contabilidade de custos. 9. ed. São Paulo: Atlas, 2003.

MCGEEVER, C. Business Intelligence. Computerworld. Arizona, p.54, jul-2000.

MCGEE, James; PRUSAK, Laurence. Gerenciamento estratégico da informação. Rio de Janeiro: Campus, 1994.

MOSCOVE, S.; SIMKIN, M.; BAGRANOFF, N. Sistemas de informações contábeis. São Paulo: Atlas, 2002.

O’ BRIEN, J. Sistemas de informação e as decisões gerenciais na era da Internet. São Paulo: Saraiva, 2004.

PADOVEZE, Clóvis L. Controladoria estratégica e operacional: conceitos, estrutura, aplicação. São Paulo: Thomson, 2003

PETRINI, M.; POZZEBON, M.; FREITAS, M. T. Qual é o Papel da Inteligência de Negócios (BI) nos Países em Desenvolvimento? Um Panorama das Empresas Brasileiras. In: Anais do 28 Encontro da ENANPAD, Curitiba - PN, setembro de 2004.

REZENDE, D.A.; ABREU, A. F. Tecnologia da informação aplicada a sistemas de informação empresariais. São Paulo: Atlas 2003.

ROEHL-ANDERSON, J. M.; BRAGG, S.M. Manual del Controller: Funciones, procedimientos y responsabilidades. Deusto: Barcelona, 1996. STEINER, George A; MINER, John B. Política e estratégia administrativa. São Paulo: Editora da Universidade de São Paulo, 1981.

TUNG, Nguyen H. Controladoria financeira das empresas: uma abordagem prática. 8 ed. São Paulo: Edições Universidade-empresa, 1993. WRIGHT, Peter; KROLL, Mark J.; PARNELL, John. Administração estratégica: conceitos. São Paulo: Atlas, 2000.

\section{NOTA - Endereço dos autores}

Universidade do Vale do Rio dos Sinos

Av. Unisinos, 950 - Cristo Rei

São Leopoldo - RS

93.022-000 